University of Nebraska - Lincoln

DigitalCommons@University of Nebraska - Lincoln

CSE Conference and Workshop Papers

Computer Science and Engineering, Department

1998

\title{
BER-Based Call Admission In Wavelength-Routed Optical Networks
}

\author{
Debasish Datta \\ University of California, Davis \\ Byrav Ramamurthy \\ University of Nebraska-Lincoln, bramamurthy2@unl.edu \\ Helena Feng \\ University of California, Davis \\ Jonathan P. Heritage \\ University of California, Davis \\ Biswanath Mukherjee \\ University of California, Davis
}

Follow this and additional works at: https://digitalcommons.unl.edu/cseconfwork

Part of the Computer Sciences Commons

Datta, Debasish; Ramamurthy, Byrav; Feng, Helena; Heritage, Jonathan P.; and Mukherjee, Biswanath, "BER-Based Call Admission In Wavelength-Routed Optical Networks" (1998). CSE Conference and Workshop Papers. 63.

https://digitalcommons.unl.edu/cseconfwork/63

This Article is brought to you for free and open access by the Computer Science and Engineering, Department of at DigitalCommons@University of Nebraska - Lincoln. It has been accepted for inclusion in CSE Conference and Workshop Papers by an authorized administrator of DigitalCommons@University of Nebraska - Lincoln. 
form an arbitrary physical topology. A new call is admitted into the network if an all-optical lightpath can be established between the call's source and destination nodes. Wavelength converters are assumed absent in this work.

Previous networking studies have concentrated on the routing and wavelength assignment (RWA) problem to set up lightpaths while assuming an ideal physical layer. ${ }^{1}$ It should, however, be noted that a signal degrades in quality as a result of physical-layer impairments as it proceeds through XCSs (picking up cross talk) and erbium-doped fiber amplifiers (EDFAs) (picking up amplified spontaneous emission (ASE) noise). As a result, the bit error rate (BER) at the receiving end of a lightpath may become unacceptably high.

The objective of the present work is to estimate the on-line BER on candidate routes and wavelengths before setting up a call. Note that the existence of other calls currently in progress, i.e., traffic variation, will affect the BER estimate (because they will affect the cross talk in XCSs and the wavelength dependence and saturation of gains and ASE noise generation in EDFAs). One approach would be to set up a call on a lightpath with minimum BER. Another approach to call admission would be to establish a call on any lightpath with a BER lower than a certain threshold (e.g., $10^{-9}$ ); if no such lightpath is found, the call is blocked. Our work examines this problem. (Additional details of our approach, including a simulator that we have developed, can be found in Ref. 2.)

This computation, during call admission, requires (1) the enumeration of all the events of signal, cross talk, and ASE noise generation and (2) their subsequent losses and gains at each node along the respective lightpaths. Consider that a lightpath is to be established on wavelength $\lambda_{i}$ between the nodes 1 and $N$ [see Fig. 1(a)]. We express at the output of a $k^{\text {th }}$ intermediate node [see Fig. 1(a)], the outbound powers of the signa] $\left(p_{\text {sig }}\left(k, \lambda_{i}\right)\right)$, cross talk $\left(p_{x t}\left(k, \lambda_{i}\right)\right)$, and ASE noise $\left(p_{\text {ase }}\left(k, \lambda_{i}\right)\right)$ at $\lambda_{i}$, using the following recursive equations:

$$
\begin{aligned}
& p_{\text {sig }}\left(k, \lambda_{i}\right)=p_{\text {sig }}\left(k-1, \lambda_{i}\right) L_{f}(k-1, k) \\
& \times G_{i n}\left(k, \lambda_{j}\right) L_{d m}(k) L_{s w}(k) L_{m x}(k) G_{\text {out }}\left(k, \lambda_{i}\right) L_{\text {tap }}^{2} ; \\
& p_{x i}\left(k, \lambda_{i}\right)=p_{x i}\left(k-1, \lambda_{i}\right) L_{f}(k-1, k) \\
& \times G_{i n}\left(k, \lambda_{i}\right) L_{d m}(k) L_{s w}(k) L_{m x}(k) G_{\text {out }}\left(k, \lambda_{i}\right) L_{\text {tap }}^{2} \\
& +\sum_{j=1}^{3 k} X_{s w} p_{i n, j}(k) L_{s w}(k) L_{m x}(k) G_{o u t}\left(k, \lambda_{i}\right) L_{\text {tap }} \text {; } \\
& p_{\text {ase }}\left(k, \lambda_{i}\right)=p_{\text {ase }}\left(k-1, \lambda_{i}\right) L_{f}(k-1, k) \\
& \times G_{i n}\left(k, \lambda_{i}\right) L_{d m}(k) L_{s w}(k) L_{m x}(k) G_{o u t}\left(k, \lambda_{i}\right) L_{t a p}^{2} \\
& +n_{s p}\left[G_{i n}\left(k, \lambda_{i}\right)-1\right] h v_{i} B_{o} L_{d m}(k) L_{s w}(k) L_{m x}(k) \\
& \times G_{\text {out }}\left(k, \lambda_{i}\right) L_{\text {tap }}+n_{\text {sp }}\left[G_{\text {out }}\left(k, \lambda_{i}\right)-1\right] h v_{i} B_{0} L_{\text {tap }} .
\end{aligned}
$$

BER-based call admission in wavelength-routed optical networks

Debasish Datta, Byrav Ramamurthy, Helena Feng,* Jonathan P. Heritage,** Biswanath Mukherjee, Department of Computer Science, University of California, Davis, California 95616; E-mail: datta@cs.ucdavis.edu

Consider a wavelength-routed optical network in which nodes, i.e., multiwave length cross-connect switches (XCSs), are connected by fiber to

The loss and gain variables for various network components used above (generically, $L_{x}(k)$ for losses, and $G_{x}\left(k, \lambda_{i}\right)$ for gains) are indicated in Fig. $1(a)$. Further, $p_{i n, j}$ is the power of the $j^{\text {th }}$ co-propagating signal at the switch (Spanke's architecture ${ }^{3}$ ) shared by the desired signal (i.e., the switch for $\lambda_{i}$ ) in the $k^{\text {th }}$ node contributing to a first-order homowavelength cross talk (crosstalk ratio $=X_{s w}$ ) with $J_{k}$ being the total number of such crosstalk sources in the $k^{\text {th }}$ node. $B_{o}$ is the optical filter bandwidth, $h$ is Planck's constant, $v_{i}$ is the optical frequency at $\lambda_{i}$, and $n_{s p}$ represents the spontaneous emission factor for the EDFAs. The EDFA gains, $G_{i n}\left(k, \lambda_{i}\right)$ and $G_{o u t}\left(k, \lambda_{i}\right)$, for each 


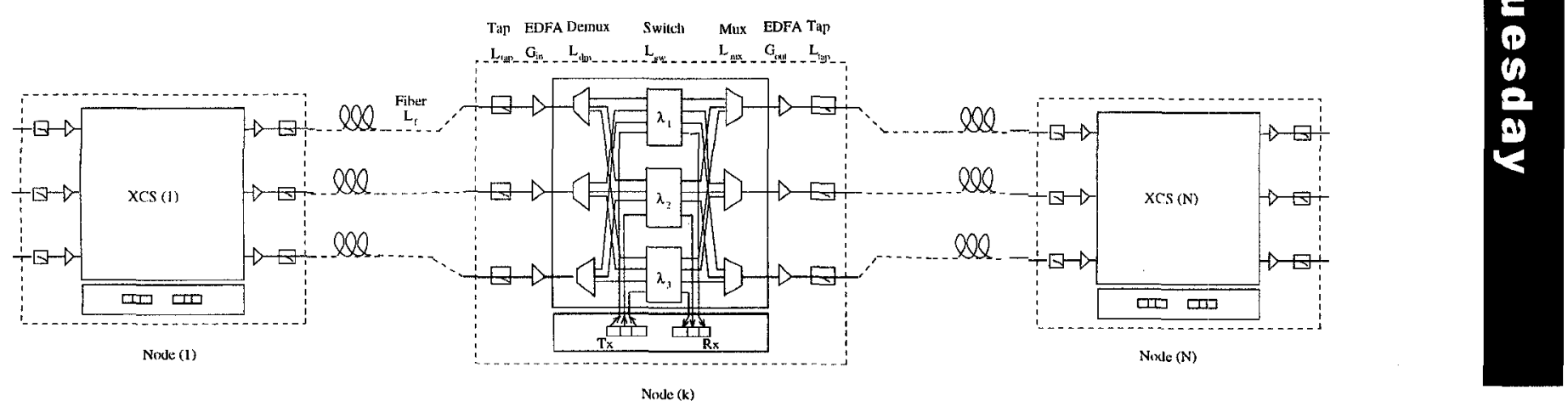

TuP4 Fig. 1. Network components in a wavelength-routed optical network.

node at all the wavelengths are evaluated using a simplified model, ${ }^{2}$ similar to Ref. 4, which takes into account the major physical phenomena in EDFAs, such as multiwavelength signal propagation, and self-saturation and cross-saturation of the EDFA gains by the trafficdependent signal channels.

Having completed the enumeration process as above till the $N^{\text {th }}$ node, the BER evaluation module computes the powers of the composite electrical noise for binary zero and one receptions, which include the receiver thermal and shot noise components and the electrical noise components resulting from the signal cross talk and signal-ASE beats. The composite electrical noise powers and the received photocurrent are then used to evaluate the BER by using a Gaussian model for the receiver. ${ }^{5}$

We apply our on-line BER-based call admission approach to a bi-directional ring network with 12 nodes, $100-\mathrm{km}$ internode distance, eight wavelengths per fiber, eight-wavelength transmitter and receiver arrays at each node, transmitted power $=1 \mathrm{~mW}, L_{m x}=L_{d m}=4 \mathrm{~dB}, L_{s w}$ $=10 \mathrm{~dB}, L_{\text {tap }}=1 \mathrm{~dB}, X_{\text {sw }}=20 \mathrm{~dB}, G_{\text {in }}(\max )=22 \mathrm{~dB}, G_{\text {out }}(\max )=16$ $\mathrm{dB}$, and shortest-path routing of lightpaths.

First, we consider a tagged call that is set up from node 10 to node 4 on wavelength $\lambda_{1}$ through the intermediate nodes $9,8,7,6$, and 5 . At this time, the other ongoing calls are from 1 to 10,7 to 12,3 to 1 , and 6 to 7 , all on the same wavelength $\left(\lambda_{1}\right)$. Figure 2 shows the powers of the received signal, ASE noise, and cross talk at the destination node (4) and at the intermediate nodes. Note that the signal power drops as the call propagates due to inadequate loss compensation and EDFA gain saturation; also, the cross talk for this tagged call follows a similar

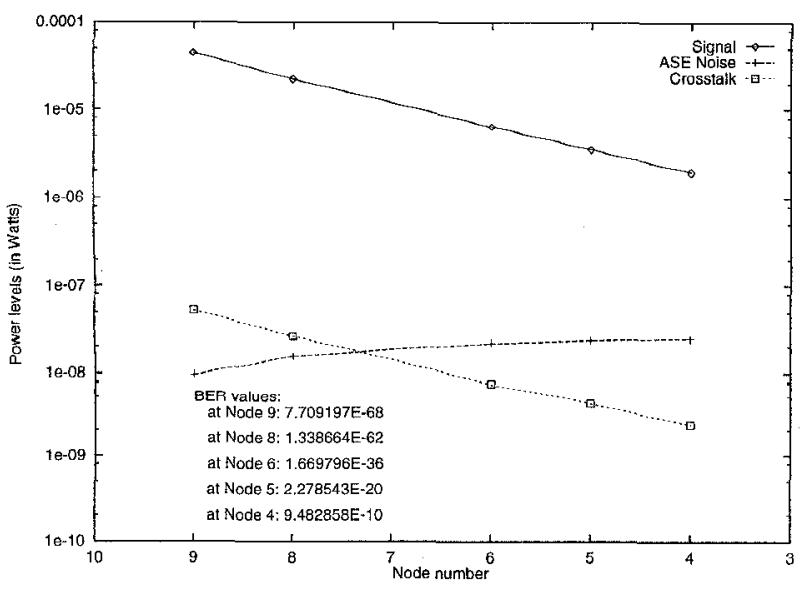

TuP4 Fig. 2. Power levels at different receivers. profile as the signal due to absence of any fresh cross talk en route. However, the ASE noise grows due to accumulation of ASE at each EDFA stage.

Figure 3 shows the blocking probability versus load characteristics in our example ring network with and without BER constraints. Both approaches employ the first-fit algorithm where the first available wavelength in a predetermined order is used to set up a call. Note the large gap in blocking probability between the ideal case (without $B E R$ ) and the actual situation (with BER $\leq 10^{-6}$ ). Although the blocking probability using BER consideration is higher than the ideal (especially so for light loads), it offers a realistic estimate of the actual blocking probability.

* Department of Applied Sciences, University of California, Davis, California 95616

** Department of Electrical and Computer Engineering, University of California, Davis, California 95616

1. R. Ramaswami and K.N. Sivarajan, IEEE/ACM Trans. Networking 3, 489-500 (1995).

2. B. Ramamurthy, D. Datta, H. Feng, J.P. Heritage, B. Mukherjee, Tech. Rep. CSE-97-7, UC Davis Computer Science Dept. (September 1997).

3. R.A. Spanke, IEEE J. Quantum Electron. 22, 1986 (1986).

4. C.R. Giles and E. Desurvire, IEEE J. Lightwave Technol. 9, 271-283 (1991).

5. H. Takahashi, K. Oda, H. Toba, IEEE J. lightwave Technol. 14, 1097-1105 (1996).

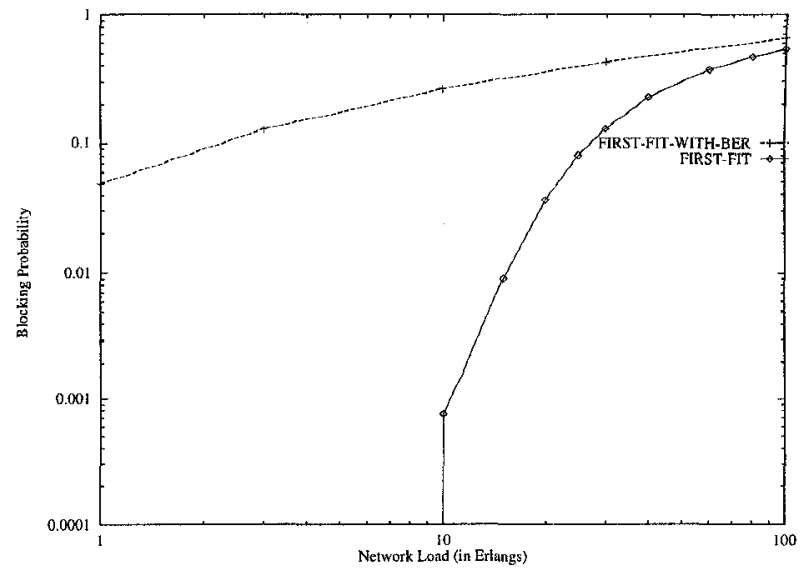

TuP4 Fig. 3. Load vs. blocking probability. 